\title{
High titer ethanol and lignosulfonate production from SPORL pretreated poplar at pilot scale
}

\author{
Haifeng Zhou ${ }^{1,2}$, J. Y. Zhu ${ }^{2}$, Roland Gleisner ${ }^{2}$, Xueqing Qiu ${ }^{3}$ and Eric Horn ${ }^{4}$ \\ ${ }^{1}$ Key Laboratory of Low Carbon Energy and Chemical Engineering, Shandong University of Science and Technology, Qingdao, China \\ ${ }^{2}$ Forest Products Laboratory, USDA Forest Service, Madison, WI, USA \\ ${ }^{3}$ School of Chemistry and Chemical Engineering, South China University of Technology, Guangzhou, China \\ ${ }^{4}$ BioPulping International, Inc., Madison, WI, USA
}

Edited by:

Soo-Jeong Shin, Chungbuk National University, South Korea

Reviewed by:

Rajeev Kumar Sukumaran, National Institute for Interdisciplinary Science and Technology, India

Yunqiao Pu, Georgia Institute of

Technology, USA

*Correspondence:

J. Y. Zhu, Forest Products Laboratory, 1 Gifford Pinchot Dr., Madison, WI,

USA

e-mail: jzhu@fs.fed.us
Poplar NE222 (Populus deltoides Bartr. ex Marsh $\times$ P. nigra L.) wood chips were pretreated in a $390 \mathrm{~L}$ pilot-scale rotating wood-pulping digester using a dilute sulfite solution of approximately $\mathrm{pH} 1.8$ at $160^{\circ} \mathrm{C}$ for $40 \mathrm{~min}$ for bioconversion to ethanol and lignosulfonate (LS). An estimated combined hydrolysis factor (CHF) of 3.3 was used to scale the sulfite pretreatment temperature and time from laboratory bench scale experiments, which balanced sugar yield and inhibitor formation to facilitate high titer ethanol production through fermentation using S. cerevisiae $\mathrm{YRH} 400$ without detoxification. A terminal ethanol titer of $43.6 \mathrm{~g} \mathrm{~L}^{-1}$ with a yield of $247 \mathrm{~L}$ tonne wood ${ }^{-1}$ was achieved at total solids loading of $20 \%$. The relatively low ethanol yield compared with yield from Sulfite pretreatment to overcome the recalcitrance of lignocelluloses (SPORL)-pretreated softwoods was due to inefficient utilization of xylose. The LS from SPORL has a substantially higher phenolic group (Ph$\mathrm{OH}$ ) content, though it was less sulfonated and had a lower molecular weight than a purified commercial softwood LS, and therefore has potential for certain commercial markets and future novel applications through further processing. The conversion efficiency achieved through process integration and simplification, demonstrated here, has significant importance to the entire supply chain of biofuel production from woody biomass.

Keywords: forest biorefinery, biofuel, process scale-up, high solids fermentation, enzymatic saccharification/hydrolysis, lignosulfonate, poplar wood

\section{INTRODUCTION}

Biomass from short rotation woody crops has been considered a viable feedstock for producing biofuels and bioproducts using the forest biorefinery concept to reduce our reliance on fossil fuel, mitigate climate change, and stimulate rural economic development (Zhu and Pan, 2010; Zalesny et al., 2011). Poplar woods can grow on marginal lands to conserve water, recycle nutrients, and sequester carbon (Vance et al., 2010) and therefore are especially attractive as a feedstock. Many efforts, from transgenic plant and plantation research (Zalesny et al., 2012; Acker et al., 2014), to pretreatment (Wyman et al., 2009; Wang et al., 2012), engineering microorganism for xylose fermentation (Ho et al., 1998; Jeffries and Jin, 2004; Wei et al., 2013), and economic analysis (Littlewood et al., 2014) have been made for efficient bioconversion of poplar woods. However, achieving high titer biofuel production from poplar woods remains a challenge; because, the chemical pretreatment step required for removing the recalcitrance of poplars for efficient enzymatic saccharification often produces inhibitors that cause difficulties in downstream processing. Unlike softwoods, the cell wall of poplar woods are highly acetylated (Gille and Pauly, 2012) to result in high concentration of acetic acid in the pretreatment hydrolyzate to substantially inhibit yeast fermentation (Palmqvist and Hahn-Hagerdal, 2000; Klinke et al., 2004; Tian et al., 2011). The compounding inhibition effect of acetic acid with furans and aromatics
(Palmqvist et al., 1999) made fermentative cellulosic ethanol production from poplar woods more challenging than from softwoods. Reported studies were limited to using washed solids alone or at low solid loadings when pretreatment hydrolyzate (spent liquor) was used to avoid fermentation difficulties without detoxification (Zhu et al., 2011; Kim et al., 2013; Kundu et al., 2014).

Sulfite pretreatment to overcome the recalcitrance of lignocelluloses (SPORL) (Zhu et al., 2009) has demonstrated robust performance for high titer and high yield ethanol production from softwood biomass without detoxification (Zhou et al., 2013b, 2015; Zhu et al., 2015). Building upon the success of SPORL, we demonstrated SPORL optimization for bioconversion of a poplar wood in laboratory bench scale $(1 \mathrm{~L})$ experiments using a combined hydrolysis factor $(\mathrm{CHF})$ to control pretreatment severity at $C H F \approx 2$, which allowed us to successfully achieve high titer $\left(>40 \mathrm{~g} \mathrm{~L}^{-1}\right)$ ethanol production without detoxification using an engineered Saccharomyces cerevisiae (Zhang et al., 2015). The objectives of the present study were to: (1) demonstrate SPORL at a pilot scale for high titer ethanol production from poplar NE222 without detoxification, (2) further validate the approach of using CHF to optimize high titer ethanol production from poplars, and (3) analyze the properties of lignosulfonate (LS) as a potential lignin coproduct. The goal of the study is to demonstrate an efficient conversion system with respect to optimizing pretreatment and simplifying 
downstream processing, important to the entire supply chain of bioethanol production from woody biomass.

\section{MATERIALS AND METHODS WOOD CHIPS}

Logs of poplar NE222 (Populus deltoides Bartr. ex Marsh $\times$ P. nigra L.) were harvested from Hugo Sauer Nursery in Rhinelander, WI, USA, and provided by the Institute for Applied Ecosystem Studies of the USDA Forest Service Northern Research Station. The logs were hand-debarked and then chipped at USDA Forest Products Laboratory, Madison, WI, USA. The screenaccepted wood chips ranged from 6 to $38 \mathrm{~mm}$ in length and 1 to $5 \mathrm{~mm}$ in thickness. The chips were kept frozen at $-16^{\circ} \mathrm{C}$ until used. The chemical composition of the wood chips is listed in Table 1.

\section{CHEMICALS, ENZYMES, AND YEAST}

Folin Ciocalteau's phenol reagent $(2 \mathrm{~N})$, vanillin, sodium acetate, acetic acid, sodium bisulfite, and sulfuric acid in ACS reagent grade were purchased from Sigma-Aldrich (St. Louis, MO, USA). High purity sodium LS (D-748) from acid sulfite pulping of softwoods was donated by LignoTech USA (Rothschild, WI, USA).

Commercial cellulase enzymes Cellic ${ }^{\circledR}$ CTec3 (abbreviated CTec3) was complimentary provided by Novozymes North America (Franklinton, NC, USA). The calibrated filter paper activity of CTec3 was $217 \mathrm{FPU} \mathrm{mL}^{-1}$ (Wood and Bhat, 1988).

Saccharomyces cerevisiae YRH400 was engineered for xylose fermentation (Hector et al., 2011) and provided by USDA Agricultural Research Service, National Center for Agriculture Utilization
Research, Peoria, IL, USA. The strain was first grown on YPD agar plates and then cultured in a liquid YPD medium in a flask overnight on a shaking bed incubator (Thermo Fisher Scientific, Model 4450, Waltham, MA, USA) as described previously (Zhou et al., 2014a). The concentration of the cultured biomass was monitored by measuring the optical density at $600 \mathrm{~nm}\left(\mathrm{OD}_{600 \mathrm{~nm}}\right)$ using a UV-Vis spectrometer (Model 8453, UV-visible spectroscopy system, Agilent Technologies, Palo Alto, CA, USA).

\section{SPORL PROCESS SCALE-UP DESIGN}

Many issues need to be taken into consideration in lignocellulose biomass pretreatment process scale-up. For example, whether or not the optimal pretreatment conditions obtained at laboratory scale be applicable at the pilot-scale? Furthermore, one also needs to consider the productivity of lignin coproduct for improving process economics. In the pulp and paper industry, the $\mathrm{H}$-factor (Vroom, 1957), i.e., the integration of temperature over time, or thermal energy input, is used for controlling alkaline pulping for delignification. Similarly, we developed a $C H F$ that can be used to describe hemicellulose yield $X_{R}$ (or dissolution) (Zhu et al., 2012) during pretreatment.

$$
\begin{aligned}
\mathrm{CHF} & =e^{\left(\alpha-\frac{E}{\mathrm{RT}}+\beta C_{\mathrm{A}}+\gamma C_{\mathrm{B}}\right)}\left(C_{\mathrm{A}}+C_{\mathrm{B}}\right) t \\
X_{\mathrm{R}} & =(1-\theta) \mathrm{e}^{-\mathrm{CHF}}+\theta \mathrm{e}^{-\mathrm{f} \mathrm{CHF}}
\end{aligned}
$$

where $C_{\mathrm{A}}$ and $C_{\mathrm{B}}$ are the concentrations of chemical $A$ (sulfuric acid) and chemical $B$ (sodium bisulfite) used in the present study, respectively. $R=8.314 \mathrm{~J} \mathrm{~mole}^{-1} \mathrm{~K}^{-1}$ is the universal gas content, $t$ is in min, $T$ is absolute temperature $(\mathrm{K})$. For poplar NE222 (Zhang et al., 2015), the adjustable parameters are $\alpha=34.5, \beta=18.6$

Table 1 | Wood component recoveries from pilot-scale SPORL pretreatment of poplar NE222 along with the chemical composition of the

\begin{tabular}{|c|c|c|c|c|c|}
\hline & $\begin{array}{l}\text { Untreated } \\
\text { wood }\end{array}$ & Unwashed solids $^{a}$ & $\begin{array}{l}\text { Collected spent } \\
\text { liquor }^{a}\end{array}$ & $\begin{array}{l}\text { Total } \\
\text { recovery (\%) }\end{array}$ & Washed solids (\%) \\
\hline Wet weight (kg) & 81.90 & 110.70 & 32.15 & & \\
\hline Solids $(\mathrm{kg})^{\mathrm{b}}$ & 40.9 & $36.45 ; 89.2 \%$ & $3.58 ; 8.8 \%$ & 97.9 & $27.52 ; 67.3 \%$ \\
\hline Klason lignin (\%) & $23.43 \pm 2.03$ & $18.56 \pm 0.05 ; 79.1 \%$ & $4.87 ; 20.8 \%$ & 100.0 & $16.69 \pm 0.03 ; 71.2 \%$ \\
\hline Glucan (\%) & $46.76 \pm 3.32$ & $44.36 \pm 0.52 ; 94.9 \%$ & $0.10 ; 0.2 \%$ & 95.1 & $40.83 \pm 0.69 ; 87.3 \%$ \\
\hline Mannan (\%) & $2.84 \pm 0.03$ & $1.86 \pm 0.20 ; 65.6 \%$ & $0.18 ; 6.5 \%$ & 72.1 & $1.31 \pm 0.03 ; 46.3 \%$ \\
\hline Xylan (\%) & $12.74 \pm 0.05$ & $8.65 \pm 0.06 ; 67.9 \%$ & $1.74 ; 13.6 \%$ & 81.5 & $3.24 \pm 0.26 ; 25.4 \%$ \\
\hline $\operatorname{HMF}(\%)^{\mathrm{c}}$ & & $0.11 ; 3.9 \%$ & $0.05(0.5) ; 1.7 \%$ & 5.5 & \\
\hline Furfural $(\%)^{\mathrm{c}}$ & & $0.59 ; 4.6 \%$ & $0.26(2.4) ; 2.0 \%$ & 6.7 & \\
\hline
\end{tabular}
untreated NE222.

The pretreatment was conducted in a 390 L rotating wood-pulping digester with sulfuric acid and sodium bisulfite loading on wood 1.1 and 3 wt $\%$, respectively, for $40 \mathrm{~min}$ at $160^{\circ} \mathrm{C}$.

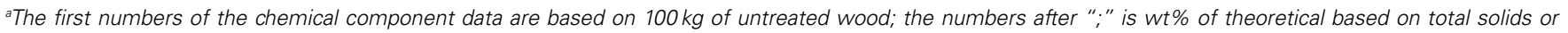
component mass in the amount of untreated wood.

${ }^{b}$ In oven dry (od) weight based on untreated wood.

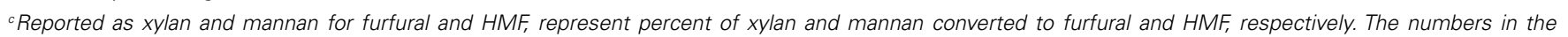
parentheses are concentration measured in the collected spent liquor in $\mathrm{g} \mathrm{L}^{-1}$. 
$\left(\mathrm{L} \mathrm{mole}^{-1}\right)$, and $\gamma=-9.7\left(\mathrm{~L} \mathrm{~mole}^{-1}\right)$, the apparent activation energy is $E=126,200 \mathrm{~J} \mathrm{~mole}^{-1}$, the initial fraction of slow reacting hemicelluloses is $\theta=0.178$, and the ratio of the hydrolysis reaction rate constant between the slow and fast hemicelluloses is $f=0.0784$. The utility of $C H F$ is that it can provide reasonably good predictions of sugar yield during subsequent enzymatic hydrolysis (Zhu et al., 2012; Zhang et al., 2015). This is because xylan dissolution that can be accurately predicted by $\mathrm{CHF}$, dictates substrate enzymatic saccharification for lignocelluloses with low lignin content such as hardwoods and herbaceous biomass (Yang and Wyman, 2004; Moxley et al., 2012; Zhu et al., 2012; Leu and Zhu, 2013; Zhang et al., 2013).

In our previous laboratory study using the same NE222 wood chips (Zhang et al., 2015), we demonstrated that optimal sugar yield can be obtained when achieving complete dissolution of fast xylan, i.e., $X_{\mathrm{R}}=\theta$, corresponding to $C H F=3.1$. We recommended using a lower $C H F \approx 2$ to balance sugar yield with inhibitor formation. Good ethanol yield, however, was achieved up to $C H F=2.7$. Fermentation was viable even at $C H F=3.5$ with a reduction in ethanol yield of approximately $25 \%$ compared with that at $C H F \approx 2.0$. Based on these guidelines, we targeted a maximum threshold $C H F=2.7$ for pretreatment at the pilot scale. We conducted SPORL using the same liquor to wood ratio of $3: 1\left(\mathrm{~L} \mathrm{~kg}^{-1}\right)$ and sulfuric acid concentration of $2 \mathrm{~mL} \mathrm{~L}^{-1}$, but with a slightly lower sodium bisulfite charge on wood of $3.0 \mathrm{wt} \%$, and at a high temperature of $160^{\circ} \mathrm{C}$ to reduce pretreatment duration. Based on Eq. 1, the required pretreatment time was $t=45 \mathrm{~min}$.

\section{PILOT-SCALE PRETREATMENT}

NE222 wood chips, weighing $81.9 \mathrm{~kg}$ with moisture content of $50.1 \%$ (40.87 kg OD weight), were pretreated in the $390 \mathrm{~L}$ stainless steel (317), steam jacketed pilot-scale wood-pulping digester. The pretreatment sulfite liquor was made up in $81.5 \mathrm{~L}$ of city water using $1.226 \mathrm{~kg}$ of sodium bisulfite and $0.45 \mathrm{~kg}$ of sulfuric acid. The digester was placed under a vacuum to approximately $635 \mathrm{~mm}$ mercury after the chips were loaded. The liquor was then completely injected into the bottom of the digester using atmospheric pressure and appropriate plumbing connections. The digester was then rotated at $2 \mathrm{rpm}$ to provide mixing while being heated by steam in the outer jacket. The temperature of the digester reached $160^{\circ} \mathrm{C}$ in $30 \mathrm{~min}$ (ramping time) and then maintained for $40 \mathrm{~min}$. The effective pretreatment time was estimated to be $40+0.5 \times 30$ (ramping time $)=55 \mathrm{~min}$ (because of the approximate linear temperature ramping), which resulted in an estimated pretreatment severity $C H F=3.3$, slightly higher than our initial target of 2.7. As described previously (Zhang et al., 2015; Zhu et al., 2015), the digester contents were discharged into a blow tank through a stainless steel pipe at the end of pretreatment. Volatiles and noncondensable gasses including $\mathrm{SO}_{2}$ were vented to a wet scrubber (Figure 1). The pretreated materials were recovered in two fractions: the freely drainable liquor of $32.15 \mathrm{~kg}$ and wet solids of $110.70 \mathrm{~kg}$ that contained approximately two-thirds of the spent liquor. Detailed mass balance data are listed in Table 1.

A $1.45 \mathrm{~kg}$ aliquot of the freely drainable spent liquor was neutralized using lime and then disk refined along with $5.0 \mathrm{~kg}$ wet solids (based on the ratio of collected spent liquor and wet solids) in an atmospheric disk refiner using a disk plate gap of $1.0 \mathrm{~mm}$ (Andritz Sprout-Bauer Atmospheric Refiner, Springfield, $\mathrm{OH}, \mathrm{USA}$ ) without adding any water. The refined material, defined as whole slurry, was used for subsequent high solids enzymatic saccharification and fermentation. A sample of the milled whole slurry was washed for chemical composition analysis, yield determination, and enzymatic hydrolysis.

\section{ENZYMATIC HYDROLYSIS}

Enzymatic hydrolysis of the washed solids (water insoluble) was conducted at $2 \%(\mathrm{w} / \mathrm{v})$ in $100 \mathrm{~mL}$ of $50 \mathrm{mM}$ acetate buffer on a shaker/incubator (Thermo Fisher Scientific, Model 4450,

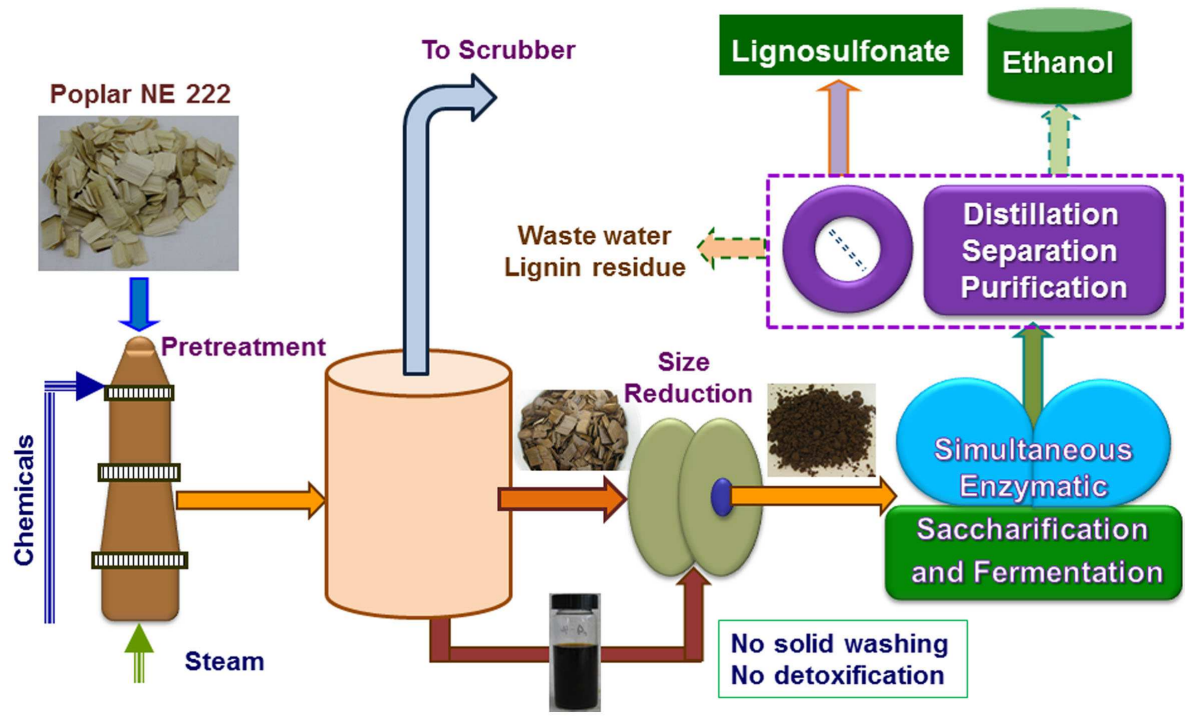

FIGURE 1 | A schematic block flow diagram shows the pilot-scale pretreatment of poplar NE222 by SPORL along with downstream enzymatic saccharification and fermentation. Process boxed by dashed lines was partially conducted. 
Waltham, MA, USA) at $50^{\circ} \mathrm{C}$ and $200 \mathrm{rpm}$ at an elevated $\mathrm{pH}$ of 5.5 as described previously (Lan et al., 2013; Lou et al., 2013; Wang et al., 2013; Zhu et al., 2015). The CTec3 enzyme loading was $10 \mathrm{FPU}_{\text {g glucan }}{ }^{-1}$. Replicate hydrolysis runs were conducted. Each sample was analyzed twice. The mean values were reported and SDs were used as error bars in plots.

\section{QUASI-SIMULTANEOUS ENZYMATIC SACCHARIFICATION AND FERMENTATION}

Q-SSF of the un-detoxified NE222 whole slurry was carried out in 125-mL Ehrlenmeyer flasks using the same shaker/incubator described above. As described previously (Lan et al., 2013; Lou et al., 2013; Wang et al., 2013; Zhu et al., 2015), fermentation was buffered at $\mathrm{pH} 5.5$ using sodium acetate $(50 \mathrm{mM})$ to reduce non-productive cellulase binding to lignin. At CTec3 loading of $26 \mathrm{~mL} \mathrm{~kg} \mathrm{untreated}$ wood $^{-1}$ liquefaction of solids was observed in about $24-26 \mathrm{~h}$ at $50^{\circ} \mathrm{C}$ and $200 \mathrm{rpm}$. The mixture was then inoculated with Saccharomyces cerevisiae YRH400 yeast seed after cooling down to $35^{\circ} \mathrm{C}$. Varied yeast seed loadings of $0.1,0.4$, and $0.6 \mathrm{mg}$ dry cellg substrate $\mathrm{e}^{-1}$ (abbreviated as $\mathrm{mgg}^{-1}$ in the following discussions), which are equivalent to calculated optical densities $\mathrm{OD}_{600 \mathrm{~nm}}=1,3.5$, and 5, respectively, were used in fermentation. No nutrients were supplemented during all fermentation runs. Duplicate fermentation runs were conducted to ensure experimental repeatability. Each sample was analyzed twice. The reported data were averages of two fermentation runs. The SDs were used as error bars in plotting.

\section{ANALYTICAL METHODS}

The chemical compositions of the untreated and pretreated NE222 were analyzed as described previously (Luo et al., 2010) using high performance anion exchange chromatography with pulsed amperometric detection (ICS-5000, Dionex, now Thermo Scientific, Sunnyvale, CA, USA). Klason lignin (acid insoluble) was quantified gravimetrically (Dence, 1992). For fast analysis, glucose in the enzymatic hydrolyzates was measured using a commercial glucose analyzer (YSI 2700S, YSI Inc., Yellow Springs, OH, USA).

Samples of fermentation broth were analyzed for monomeric sugars, furans, acetic acid, and ethanol using a HPLC system (Ultimate 3000, Thermo Scientific, Sunnyvale, CA, USA), equipped with an RI (RI-101) and UV (VWD-3400RS) detector, and using a BioRad Aminex HPX-87P, and a HPX-87H column operated as described previously (Zhou et al., 2013b). All samples were diluted using deionized water, and filtered by a $0.22 \mu \mathrm{m}$ syringe filter prior to injection.

\section{LS SEPARATION AND PURIFICATION}

The SPORL spent liquor was first filtered using Whatman filter paper then further separated and purified by ultrafiltration (142-mm Millipore Hazardous Waste Filtration System, Millipore, Ireland) using ultrafiltration membranes (Ultracel ${ }^{\circledR} 1 \mathrm{KDa}$ Ultrofiltration Disks, Millipore Corporation, Billerico, MA, USA). Detailed descriptions of the separation process can be found in our previous study (Zhou et al., 2015).

\section{GEL PERMEATION CHROMATOGRAPHY}

Aqueous GPC was conducted using an Ultrahydrogel ${ }^{\mathrm{TM}} 250$ column and measured with a multi-detector GPC system consisting of an Agilent 1100 HPLC equipped with a UV detector, an Optilab ${ }^{\mathrm{R}}$ T-rEX ${ }^{\mathrm{TM}}$ RI detector (Wyatt Technology Corp., Santa Barbara, CA, USA), and a DAWN ${ }^{\mathrm{R}}$ HELEOS $^{\mathrm{TM}}$ II (Wyatt Technology Corp.) multi-angle light scattering (MALS) detector as described previously (Zhu et al., 2015).

\section{MEASUREMENTS OF PHENOLIC GROUP AND SULFUR CONTENTS}

The phenolic group (Ph-OH) content of LS was determined as described previously (Zhou et al., 2013a). The sulfur content of LS was analyzed using inductive coupled plasma (ICP) mass spectrometry as described previously (Zhou et al., 2015).

\section{RESULTS AND DISCUSSION WOOD COMPONENT RECOVERY FROM PILOT-SCALE PRETREATMENT}

The total solids recovery from SPORL was $97.9 \%$ with $89.2 \%$ from the wet solids based on initial OD wood chips and without taking into account of the chemicals applied (Table 1). The amount of freely drainable spent liquor collected was $32.15 \mathrm{~kg}$ with additional $74.25 \mathrm{~kg}$ spent liquor remaining in the wet solids; or the wet solids contained $69.8 \%$ of the spent liquor. The amount of lignin dissolved as LS was $29.8 \%$ and was determined based on the balance of the measured Klason lignin in washed solids. Glucan loss was minimal with a total recovery of $95.1 \%$ with $87.3 \%$ from the washed solids. Xylan recovery was $81.5 \%$. The production of furfural was $6.7 \%$ expressed as the percent of xylan in untreated NE222. The furfural and acetic acid concentrations in the spent liquor were 2.4 and $13.4 \mathrm{~g} \mathrm{~L}^{-1}$, respectively, in agreement with those from our laboratory study reported previously (Zhang et al., 2015). These levels of inhibitors can support viable fermentation using YRH400.

\section{ENZYMATIC DIGESTIBILITY OF WASHED SOLIDS}

The washed solid substrate enzymatic digestibility (SED), defined as the percentage of glucan in the washed solids, enzymatically saccharified to glucose reached $88 \%$ in $72 \mathrm{~h}$ as shown in Figure 2

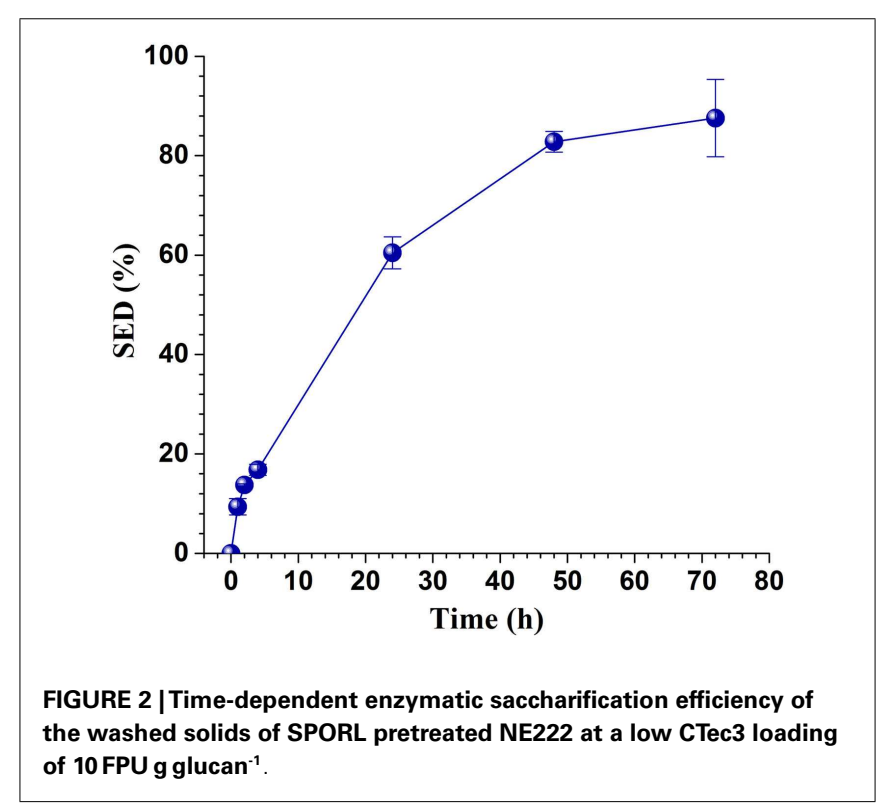


at a low CTec3 loading of $10 \mathrm{FPU}_{\text {g glucan }}{ }^{-1}$ or $19 \mathrm{~mL} \mathrm{~kg} \mathrm{untreated}$ wood $^{-1}$. This indicated that the pretreatment was effective.

\section{FERMENTATION OF UN-DETOXIFIED PRETREATED WHOLE SLURRY AT HIGH SOLIDS}

Q-SSF of the whole slurry of SPORL pretreated NE222 was conducted at $20 \%$ total solids loading without detoxification using S. cerevisiae YRH400. Enzymatic liquefaction (or pre-hydrolysis) produced a hydrolyzate with initial glucose concentration of approximately $70 \mathrm{~g} \mathrm{~L}^{-1}$ (Figure $3 \mathrm{~A}$, yeast added at $t=0$ ). The initial xylose concentration in the hydrolyzate was approximately $30 \mathrm{~g} \mathrm{~L}^{-1}$ (Figure 3B) along with $7 \mathrm{~g} \mathrm{~L}^{-1}$ mannose (Figure 3C). Glucose was completely consumed in $120 \mathrm{~h}$ and $72 \mathrm{~h}$ by YRH400

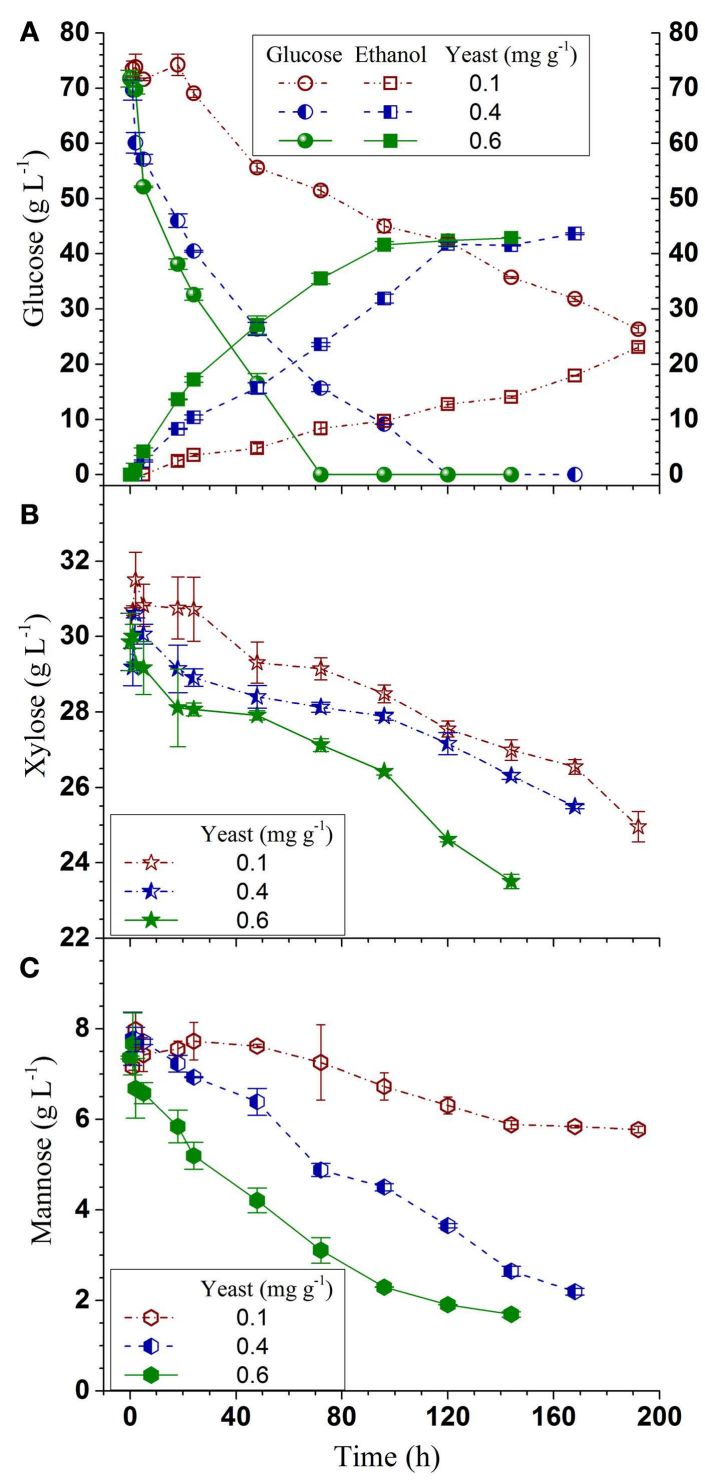

FIGURE 3 |Time-dependent ethanol production and sugar consumptions during Q-SSF of the whole slurry of SPORL pretreated NE222 at $\mathbf{2 0} \%$ total solids loading without detoxification. (A) Ethanol and glucose; (B) Xylose; (C) Mannose. at yeast loadings of $0.4 \mathrm{mgg}^{-1}\left(\mathrm{OD}_{600 \mathrm{~nm}}=3.5\right)$ and $0.6 \mathrm{mgg}^{-1}$ $\left(\mathrm{OD}_{600 \mathrm{~nm}}=5.0\right)$, respectively. However, glucose consumption was delayed for approximately $20 \mathrm{~h}$ at yeast loading $=0.1 \mathrm{mg} \mathrm{g}^{-1}$ $\left(\mathrm{OD}_{600 \mathrm{~nm}}=1.0\right)$ as shown in Figure 3A. Furthermore, glucose consumption rate was substantially reduced. The average glucose consumption in the first $48 \mathrm{~h}$ was reduced from $-0.89 \mathrm{~g} \mathrm{~L}^{-1} \mathrm{~h}^{-1}$ at yeast loading $=0.4 \mathrm{mg} \mathrm{g}^{-1}$ to $-0.33 \mathrm{~g} \mathrm{~L}^{-1} \mathrm{~h}^{-1}$ at $0.1 \mathrm{mg} \mathrm{g}^{-1}$ (Table 2), or by $63 \%$. Only approximately $25 \%$ of the xylose was consumed in $120 \mathrm{~h}$ fermentation (Figure 3B). This low xylose consumption was also observed in our previous study (Zhou et al., 2014a), especially with the presence of fermentation inhibitors. S. cerevisiae relies on hexose transporters with a low affinity for xylose (Kotter and Ciriacy, 1993). Both xylose and mannose consumptions were slower at lower yeast loadings (Figures 3B,C). Ethanol productivity was $0.35 \mathrm{~g} \mathrm{~L}^{-1} \mathrm{~h}^{-1}$ in the first $48 \mathrm{~h}$ at yeast loading of $0.4 \mathrm{mg} \mathrm{g}^{-1}$ with terminal ethanol concentration of $43.6 \mathrm{~g} \mathrm{~L}^{-1}$, compared with $0.11 \mathrm{~g} \mathrm{~L}^{-1} \mathrm{~h}^{-1}$ and $23.1 \mathrm{~g} \mathrm{~L}^{-1}$ at $0.1 \mathrm{mg} \mathrm{g}^{-1}$ yeast loading (Table 2). Further increase in yeast loading from 0.4 to $0.6 \mathrm{mg} \mathrm{g}^{-1}$ did not significantly improve terminal ethanol titer and yield, though it did improve ethanol productivity to $0.59 \mathrm{gL}^{-1}$ in the first $48 \mathrm{~h}$ (Table 2).

Acetic acid is the major inhibitor in hydrolyzates derived from hardwoods or herbaceous biomass. Acetic acid concentration was approximately $10 \mathrm{~g} \mathrm{~L}^{-1}$ in the SPORL pretreated NE222 fermentation broth throughout the fermentation process (Figure 4A) as

Table 2 | Performance of Q-SSF of the SPORL pretreated NE222 whole slurry at $20 \%$ total solids without detoxification at three yeast loadings.

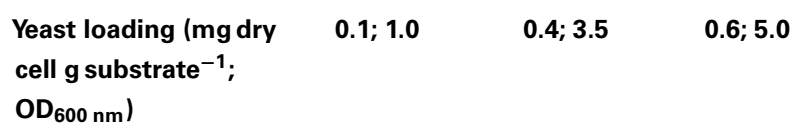

Average fermentation performance measure in the first $48 \mathrm{~h}$ unless indicated $\left(\mathrm{g} \mathrm{L}^{-1} \mathbf{h}^{-1}\right)$

$\begin{array}{llll}\text { Ethanol productivity } & 0.11 & 0.35 & 0.59\end{array}$

Glucose consumption $\quad-0.33 \quad-0.89 \quad-1.18$

Mannose consumption $\quad-0.00 \quad-0.03 \quad-0.07$

Xylose consumption $\quad-0.025 \quad-0.034 \quad-0.043$

HMF metabolization $\quad-0.003(24 \mathrm{~h}) \quad-0.005(24 \mathrm{~h}) \quad-0.005(24 \mathrm{~h})$

Furfural metabolization $\quad-0.004(18 \mathrm{~h}) \quad-0.012(18 \mathrm{~h}) \quad-0.011(18 \mathrm{~h})$

Terminal maximal ethanol production

Ethanol concentration $\quad 23.1 \pm 0.6 \quad 43.6 \pm 0.2 \quad 42.9 \pm 0.1$

$\begin{array}{llll}\left(\mathrm{g} \mathrm{L}^{-1}\right) & (192 \mathrm{~h}) & (168 \mathrm{~h}) & (144 \mathrm{~h})\end{array}$

$\begin{array}{llll}\text { Ethanol yield } \operatorname{lgg} & 0.152 \pm 0.004 & 0.287 \pm 0.001 & 0.282 \pm 0.000\end{array}$

sugar $\left.^{-1}\right)^{\mathrm{a}}$

Ethanol yield (L tonne $\quad 130.4 \pm 3.6 \quad 246.7 \pm 0.9 \quad 242.3 \pm 0.4$

wood $^{-1}$ )

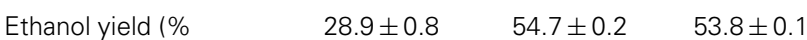

theoretical $^{\mathrm{b}}$

${ }^{a}$ Based on the total of glucan, mannan, xylan in the pretreated-solids, and glucose, mannose, and xylose in the pretreatment spent liquor.

${ }^{b}$ Theoretical yield $\left(450.7 \mathrm{~L}\right.$ tonne wood ${ }^{-1}$ from NE222) based on total glucan, mannan, xylan in the untreated wood. 


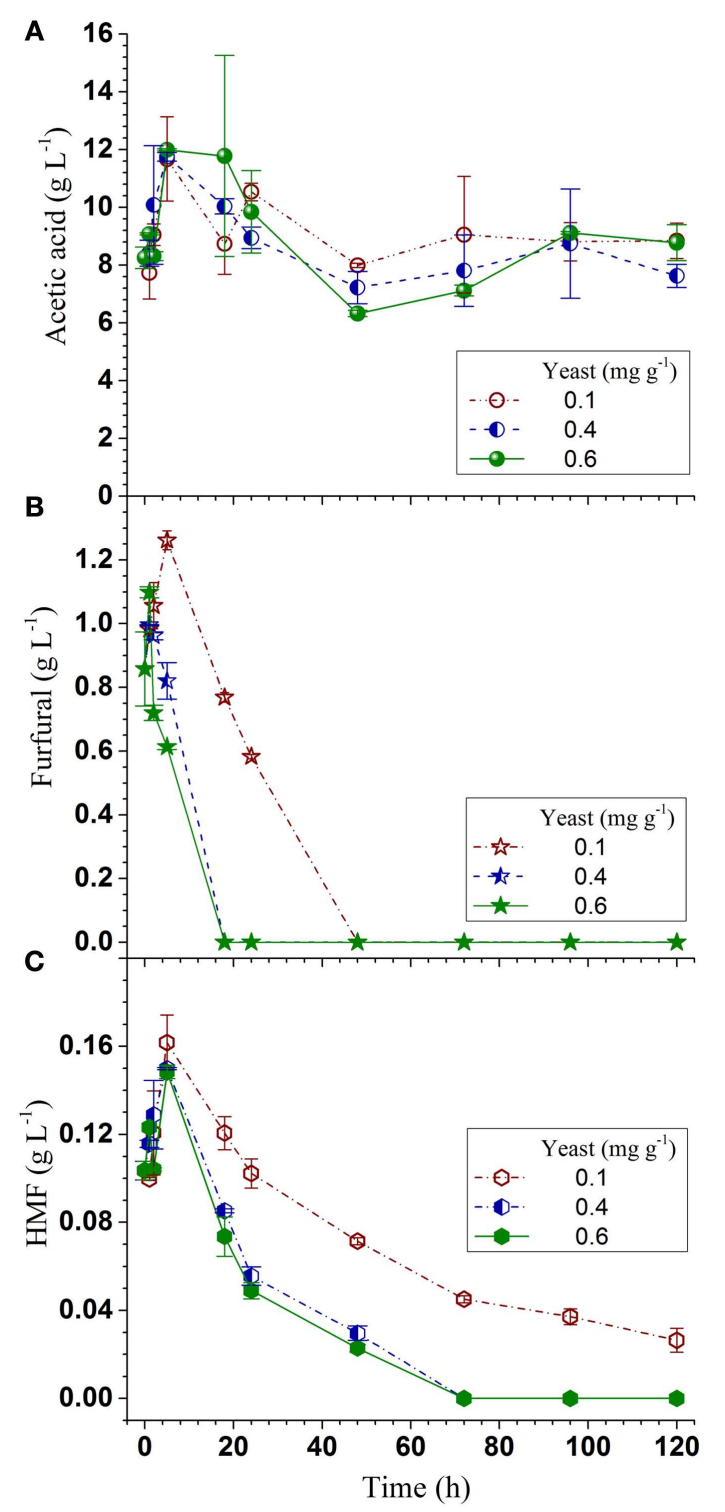

FIGURE 4 | Time-dependent inhibitor concentrations during Q-SSF of the whole slurry of SPORL pretreated NE222 at $20 \%$ total solids loading without detoxification. (A) Acetic acid; (B) Furfural; (C) HMF.

S. cerevisiae does not metabolize acetic acid (Wei et al., 2013). However, YRH400 quickly metabolized furans even at the lower yeast loading of $0.1 \mathrm{mg} \mathrm{g}^{-1}$ (Figures 4B,C). Furfural was completely metabolized within the first $20 \mathrm{~h}$ at yeast loading of $0.4 \mathrm{mg} \mathrm{g}^{-1}$. However, complete metabolization of hydroxylmethyl furfural (HMF) required $72 \mathrm{~h}$ at the same yeast loading because HMF has a lower membrane permeability (Palmqvist and HahnHägerdal, 2000). The results in Figures $\mathbf{3 A - C}$ and $\mathbf{4 A - C}$ suggested that fermentation by $\mathrm{YRH} 400$ was fairly robust even at acetic acid concentration of $10 \mathrm{gL}^{-1}$ and furan concentration of approximately $2 \mathrm{~g} \mathrm{~L}^{-1}$.

To demonstrate the effectiveness of using CHF for SPORL process scale-up, the present ethanol yield and productivity vs

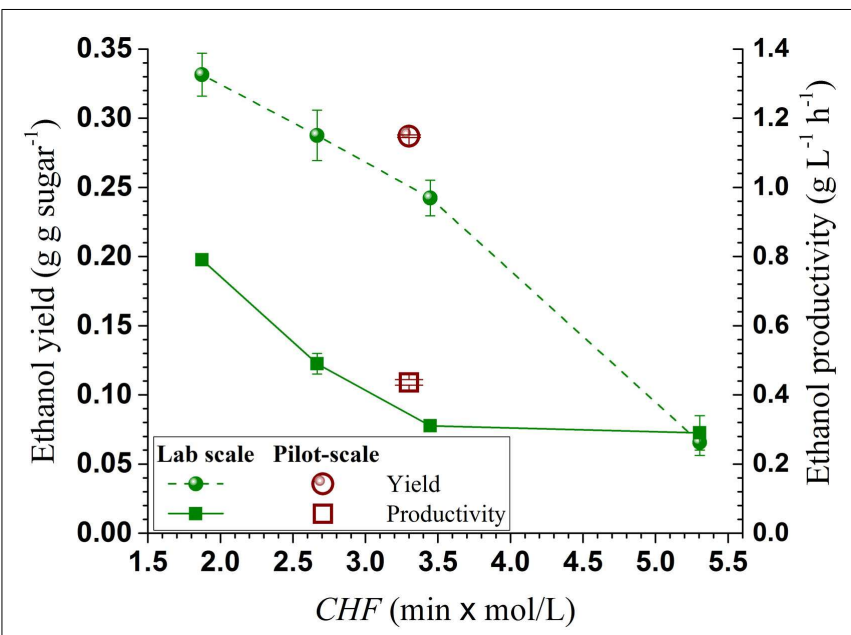

FIGURE 5 | Comparisons of ethanol productivity and yield from the present pilot-scale study $(\mathbf{4 0} \mathbf{~ k g})$ with those from a lab-bench scale study $(150 \mathrm{~g})$ plotted against pretreatment severity CHF.

pretreatment severity $\mathrm{CHF}$ were compared with those obtained at the lab bench-scale under different temperatures and a slightly higher sulfite loading of $4 \mathrm{wt} \%$ in a previous study (Zhang et al., 2015). Both ethanol productivity and yield from the pilot scale showed good agreement with the lab-bench scale data (Figure 5), indicating $C H F$ is a good scaling factor for ethanol production when using SPORL.

\section{ETHANOL YIELD AND MASS BALANCE}

The process data were used to produce the overall mass balance for the fermentation run with yeast loading of $0.4 \mathrm{mg} \mathrm{g}^{-1}$ (or $\mathrm{OD}_{600 \mathrm{~nm}}=3.5$ ). As shown in Figure 6, ethanol yield was $247 \pm 1 \mathrm{~L}(195 \mathrm{~kg})$ tonne wood $^{-1}$, or equivalent to $54.7 \%$ theoretical based on the sum of wood glucan, mannan, and xylan content. The terminal titer was $43.6 \pm 0.2 \mathrm{~g} \mathrm{~L}^{-1}$ (Table 2). These numbers are in agreement with those produced from lab scale (150 g) pretreatment (Zhang et al., 2015) using the same NE222 with $C H F=1.87-2.68$. The low ethanol yield of $54.7 \%$ theoretical compared with approximately $70 \%$ using SPORL on softwood species (Zhou et al., 2013b; Zhu et al., 2015) was mainly due to the low xylose fermentation yield. Poplar NE222 has $12.7 \%$ xylan content, only approximately $25 \%$ of the xylose was fermented as discussed previously (Figure 3B). A better xylose fermentation strain may be able to improve overall ethanol yield.

\section{PROPERTIES OF LS}

Approximately $67 \mathrm{~kg}$ wood lignin tonne wood ${ }^{-1}$ can be recovered as LS as a coproduct (Figure 6). The actual LS yield will be higher because sodium and sulfur on LS was not in the mass balance calculation. LS has a variety of commercial applications (Gargulak and Lebo, 1999). To ensure the utility of the LS produced from poplar NE222 (LS-SP-NE222) in the present study, the molecular weight (MW), sulfonic acid group, and $\mathrm{Ph}-\mathrm{OH}$ contents were compared with a commercial LS (D-748) produced from acid sulfite pulping of softwoods. As shown in Table 3, LS-SP-NE222 had a low MW of $16560 \mathrm{Da}$ compared with $43110 \mathrm{Da}$ for D-748. 


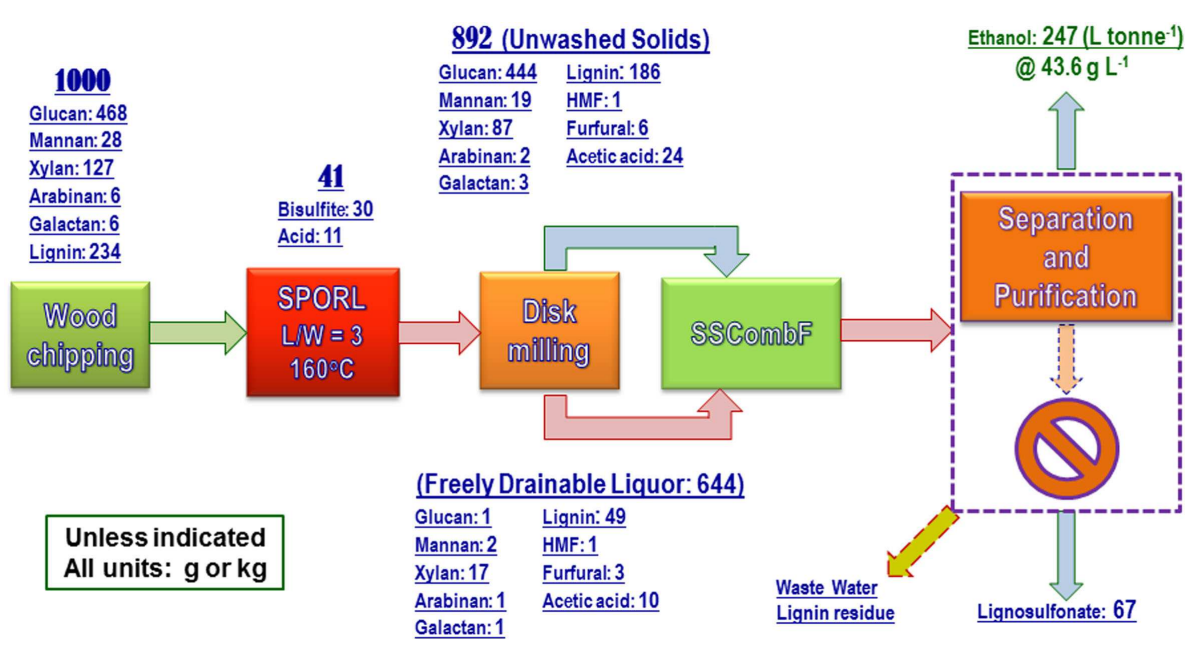

FIGURE 6 | A block diagram shows overall process mass balance for the pilot-scale pretreatment of poplar NE222 with subsequent enzymatic saccharification and fermentation. Process boxed by dashed lines was partially conducted.

LS-SP-NE222 was also less sulfonated with sulfur content of $42.5 \mathrm{mg} \mathrm{g}^{-1}$ vs $61.7 \mathrm{mg} \mathrm{g}^{-1}$ for $\mathrm{D}-748$. However, the $\mathrm{Ph}-\mathrm{OH}$ content in LS-SP-NE222 is approximately two times of that in D-748.

Typically, LSs with higher sulfur content were found to be better than those of low sulfur content as a dispersant for coal-water slurry and cement (Yang et al., 2007; Ouyang et al., 2009). A similar finding was obtained in applying LS as a dispersant to gypsum paste (Matsushita and Yasuda, 2005). This suggests the low sulfite loading used in the present SPORL pretreatment does not produce a favorable lignin coproduct for the above mentioned applications. Previous studies using high sulfite loading for softwoods produced LS with a sulfur content equivalent to as D-748 (Zhou et al., 2014b; Zhu et al., 2015). Ph-OH content affects both LS physical and chemical properties (Adler, 1977). The high content of $\mathrm{Ph}-\mathrm{OH}$ indicates the potential of LS to produce phenolic, isocyanate, and epoxy resins (Olivares et al., 1988; Lora and Glasser, 2002). In addition, $\mathrm{Ph}-\mathrm{OH}$ provides opportunities for chemical and biological modifications for developing novel applications of LS. This suggests that the LS-SP-NE222 may be more suitable for these applications.

\section{CONCLUSION}

This study demonstrated pilot-scale SPORL pretreatment of a poplar wood for high titer ethanol production without detoxification. The compounding effect of fermentation inhibition from acetic acid and furans was managed by balancing sugar yield with inhibitor formation using a $C H F$ as a pretreatment severity measure. A good ethanol yield of $247 \mathrm{~L}$ tonne wood $^{-1}$ at titer of $43.6 \mathrm{~g} \mathrm{~L}^{-1}$ was achieved at a CTec3 loading of only $15 \mathrm{FPUg}_{\text {glucan }}{ }^{-1}$ or $26 \mathrm{~mL} \mathrm{~kg} \mathrm{wood}^{-1}$ and yeast loading of $0.4 \mathrm{mgg}$ substrate $^{-1}$. LS from SPORL pretreatment had high $\mathrm{Ph}-\mathrm{OH}$ content that may be suitable for special applications to improve the economics of biofuel production. No competing technology has demonstrated the results presented in this study. SPORL was developed based on sulfite pulping with proven commercial scalability and has potential for commercialization.
Table 3 | Comparisons of MWs and sulfur and $\mathrm{Ph}-\mathrm{OH}$ contents of the LS from SPORL pretreated NE222 at the pilot scale with sulfuric acid and sodium bisulfite loading on wood 1.1 and $3.0 \mathrm{wt} \%$, respectively, for $40 \mathrm{~min}$ at $160^{\circ} \mathrm{C}$ with those of a commercial LS from sulfite pulping of softwoods.

\begin{tabular}{llllll}
\hline LS & $\mathbf{M}_{\mathbf{n}}$ (Da) & $\mathbf{M}_{\mathbf{w}}$ (Da) & $\mathbf{M}_{\mathbf{w}} / \mathbf{M}_{\mathbf{n}}$ & $\begin{array}{l}\text { Sulfur } \\
\mathbf{( m g ~ g}^{-\mathbf{1}} \mathbf{)}\end{array}$ & $\begin{array}{l}\mathbf{P h}-\mathbf{O H} \\
(\mathbf{m m o l ~ g} \mathbf{- 1})\end{array}$ \\
\hline LS-SP-NE222 & 6060 & 16560 & 2.74 & $42.5 \pm 1.4$ & $3.23 \pm 0.01$ \\
D-748 & 19002 & 43110 & 2.27 & $61.7 \pm 1.3$ & $1.63 \pm 0.01$
\end{tabular}

The study demonstrated an efficient conversion system at pilot scale, especially with respect to optimizing pretreatment by using a simple scale factor and eliminating detoxification in downstream processing. Therefore, this study is important to both the research community and industry in the entire supply chain of bioethanol production from woody biomass.

\section{ACKNOWLEDGMENTS}

This work was supported by a USDA Small Business Innovative Research (SBIR) Phase II project (Contract Number: 201033610-21589) to Biopulping International, the Chinese Scholarship Council (CSC), and the International Science and Technology Cooperation Program of China (ISTCP):2013DFA41670. The funding from these programs made the visiting appointment of $\mathrm{HZ}$ at the USDA Forest Products Laboratory (FPL) possible. We would like to acknowledge Jerry Gargulak of LignoTech for providing us the D-748 Lignosulfonate, Fred Matt for conducting carbohydrate measurements, Linda Lorenz for assisting GPC measurements of lignosulfonate, Kolby Hirth for ICP analysis of sulfur, and Ron Zalesny of the USDA Forest Service Northern Research Station for providing the wood material. This work was conducted on official government time of JYZ and RG while HZ was a visiting student at the USDA Forest Service, Forest Products Laboratory, Madison, WI, USA. 


\section{REFERENCES}

Acker, R. V., Leple, J. C., Aerts, D., Storme, V., Goeminne, G., Ivens, B., et al. (2014). Improved saccharification and ethanol yield from field-grown transgenic poplar deficient in cinnamoyl-CoA reductase. Proc. Natl. Acad. Sci. USA. 111, 845-850. doi:10.1073/pnas.1321673111

Adler, E. (1977). Lignin chemistry - past, present and future. Wood Sci. Technol. 11, 169-218. doi:10.1007/BF00365615

Dence, C. W. (1992). “The determination of lignin," in Methods in Lignin Chemistry, eds S. Y. Lin and C. W. Dence (Berlin: Springer-Verlag), 33-61.

Gargulak, J. D., and Lebo, S. E. (1999). "Commercial use of lignin-based materials," in Lignin: Historical, Biological, and Materials Perspectives, Vol. 742, eds W. G. Glasser, R. A. Northey, and T. P. Schultz (Washington, DC: American Chemical Society), 304-320.

Gille, S., and Pauly, M. (2012). O-acetylation of plant cell wall polysaccharides. Front. Plant Sci. 3:12. doi:10.3389/fpls.2012.00012

Hector, R. E., Dien, B. S., Cotta, M. A., and Qureshi, N. (2011). Engineering industrial Saccharomyces cerevisiae strains for xylose fermentation and comparison for switchgrass conversion. J. Ind. Microbiol. Biotechnol. 38, 1193-1202. doi:10.1007/s10295-010-0896-1

Ho, N. W. Y., Chen, Z., and Brainard, A. P. (1998). Genetically engineered Saccharomyces yeast capable of effective cofermentation of glucose and xylose. Appl. Environ. Microbiol 64, 1852-1859.

Jeffries, T. W., and Jin, Y.-S. (2004). Metabolic engineering for improved fermentation of xylose by yeasts. Appl. Microbiol. Biotechnol. 63, 495-509. doi:10.1007/ s00253-003-1450-0

Kim, T. H., Choi, C. H., and Oh, K. K. (2013). Bioconversion of sawdust into ethanol using dilute sulfuric acid-assisted continuous twin screw-driven reactor pretreatment and fed-batch simultaneous saccharification and fermentation. Bioresour. Technol. 130, 306-313. doi:10.1016/j.biortech.2012.11.125

Klinke, H. B., Thomsen, A. B., and Ahring, B. K. (2004). Inhibition of ethanolproducing yeast and bacteria by degradation products produced during pretreatment of biomass. Appl. Microbiol. Biotechnol. 66, 10-26. doi:10.1007/ s00253-004-1642-2

Kotter, P., and Ciriacy, M. (1993). Xylose fermentation by Saccharomyces cerevisiae. Appl. Microbiol. Biotechnol. 38, 776-783. doi:10.1007/BF00167144

Kundu, C., Lee, H. J., and Lee, J. W. (2014). Enhanced bioethanol production from yellow poplar by deacetylation and oxalic acid pretreatment without detoxification. Bioresour. Technol. 178, 28-35. doi:10.1016/j.biortech.2014.08.082

Lan, T., Lou, H., and Zhu, J. (2013). Enzymatic saccharification of lignocelluloses should be conducted at elevated pH 5.2-6.2. Bioenerg. Res. 6, 476-485. doi:10.1007/s12155-012-9273-4

Leu, S. Y., and Zhu, J. Y. (2013). Substrate-related factors affecting enzymatic saccharification of lignocelluloses: our recent understanding. Bioenerg. Res. 6, 405-415. doi:10.1007/s12155-012-9276-1

Littlewood, J., Guo, M., Boerjan, W., and Murphy, R. J. (2014). Bioethanol from poplar: a commercially viable alternative to fossil fuel in the European Union. Biotechnol. Biofuels 7, 113. doi:10.1186/1754-6834-7-113

Lora, J. H., and Glasser, W. G. (2002). Recent industrial applications of lignin: a sustainable alternative to nonrenewable materials. J. Polym. Environ. 10, 39-48. doi:10.1023/A:1021070006895

Lou, H., Zhu, J., Lan, T. Q., Lai, H., and Qiu, X. (2013). pH-Induced lignin surface modification to reduce nonspecific cellulase binding and enhance enzymatic saccharification of lignocelluloses. ChemSusChem 6, 919-927. doi:10.1002/cssc. 201200859

Luo, X., Gleisner, R., Tian, S., Negron, J., Zhu, W., Horn, E., et al. (2010). Evaluation of mountain beetle-infested lodgepole pine for cellulosic ethanol production by sulfite pretreatment to overcome recalcitrance of lignocellulose. Ind. Eng. Chem. Res. 49, 8258-8266. doi:10.1021/ie1003202

Matsushita, Y., and Yasuda, S. (2005). Preparation and evaluation of lignosulfonates as a dispersant for gypsum paste from acid hydrolysis lignin. Bioresour. Technol. 96, 465-470. doi:10.1016/j.biortech.2004.05.023

Moxley, G., Gaspar, A. R., Higgins, D., and Xu, H. (2012). Structural changes of corn stover lignin during acid pretreatment. J. Ind. Microbiol. Biotechnol. 39, 1289-1299. doi:10.1007/s10295-012-1131-Z

Olivares, M., Guzman, J. A., Natho, A., and Saavedra, A. (1988). Kraft lignin utilization in adhesives. Wood Sci. Technol. 22, 157-165. doi:10.1016/j.ultsonch.2013. 05.001
Ouyang, X., Ke, L., Qiu, X., Guo, Y., and Pang, Y. (2009). Sulfonation of alkali lignin and its potential use in dispersant for cement. J. Dispers. Sci. Technol. 30, 1-6. doi:10.1080/01932690802473560

Palmqvist, E., Grage, H., Meinander, N. Q., and Hahn-Hägerdal, B. (1999). Main and interaction effects of acetic acid, furfural, and p- hydroxybenzoic acid on growth and ethanol productivity of yeasts. Biotechnol. Bioeng. 63, 46-55. doi:10.1002/(SICI) 1097-0290(19990405)63:1<46::AID-BIT5>3.3 CO;2-A

Palmqvist, E., and Hahn-Hagerdal, B. (2000). Fermentation of lignocellulosic hydrolysate: I inhibition and detoxification. Bioresour. Technol. 74, 17-24. doi:10.1016/j.biortech.2013.03.014

Palmqvist, E., and Hahn-Hägerdal, B. (2000). Fermentation of lignocellulosic hydrolysates. II: Inhibitors and mechanisms of inhibition. Bioresour. Technol. 74, 25-33. doi:10.1016/S0960-8524(99)00161-3

Tian, S., Zhu, W., Gleisner, R., Pan, X. J., and Zhu, J. Y. (2011). Comparisons of SPORL and dilute acid pretreatments for sugar and ethanol productions from aspen. Biotechnol. Prog. 27, 419-427. doi:10.1002/btpr.545

Vance, E. D., Maguire, D. A., and Zalesny, R. S. J. (2010). Research strategies for increasing productivity of intensively managed forest plantations. J. For. 108, $183-192$.

Vroom, K. E. (1957). A means of expressing cooking times and temperatures as a single variable. Pulp Paper Mag. Can. 58, 228-231.

Wang, Z. J., Lan, T. Q., and Zhu, J. Y. (2013). Lignosulfonate and elevated pH can enhance enzymatic saccharification of lignocelluloses. Biotechnol. Biofuels 6, 9. doi:10.1186/1754-6834-6-9

Wang, Z. J., Zhu, J. Y., Zalesny, R. S. J., and Chen, K. F. (2012). Ethanol production form poplar wood the through enzymatic saccharification and fermentation by dilute acid and SPORL pretreatments. Fuel 95, 606-614. doi:10.1016/j.fuel.2011. 12.032

Wei, N., Quarterman, J., Kim, S. R., Cate, J. H. D., and Jin, Y. S. (2013). Enhanced biofuel production through coupled acetic acid and xylose consumption by engineered yeast. Nat. Commun. 4, 2580. doi:10.1038/ncomms3580

Wood, T. M., and Bhat, K. M. (1988). Methods for measuring cellulase activities. Meth. Enzymol. 160, 87-112. doi:10.1016/0076-6879(88)60109-1

Wyman, C. E., Dale, B. E., Elander, R. T., Holtzapple, M., Ladisch, M. R., Lee, Y. Y., et al. (2009). Comparative sugar recovery and fermentation data following pretreatment of poplar wood by leading technologies. Biotechnol. Prog. 25, 333-339. doi:10.1002/btpr.142

Yang, B., and Wyman, C. E. (2004). Effect of xylan and lignin removal by batch and flowthrough pretreatment on the enzymatic digestibility of corn stover cellulose. Biotechnol. Bioeng. 86, 88-95. doi:10.1002/bit.20043

Yang, D., Qiu, X., Zhou, M., and Lou, H. (2007). Properties of sodium lignosulfonate as dispersant of coal water slurry. Energy Convers. Manage. 48, 2433-2438. doi:10.1016/j.enconman.2007.04.007

Zalesny, R. S. Jr., Donner, D. M., Coyle, D. R., and Headlee, W. L. (2012). An approach for siting poplar energy production systems to increase productivity and associated ecosystem services. For. Ecol. Manage. 284, 45-58. doi:10.1016/j.foreco.2012.07.022

Zalesny, R. S. J., Cunningham, M. W., Hall, R. B., Mirck, J., Rockwood, D. L., Stanturf, J. A., et al. (2011). "Woody biomass from short rotation energy crops. 1st ed," in Sustainable Production of Fuels, Chemicals, and Fibers from Forest Biomass, eds J. Y. Zhu, X. Zhang, and X. J. Pan (Washington, DC: American Chemical Society), 27-63.

Zhang, D. S., Yang, Q., Zhu, J. Y., and Pan, X. J. (2013). Sulfite (SPORL) pretreatment of switchgrass for enzymatic saccharification. Bioresour. Technol. 129, 127-134. doi:10.1016/j.biortech.2012.11.031

Zhang, J., Gu, F., Zhu, J. Y., and Zalesny, R. S. Jr. (2015). Optimizing high titer ethanol production from a SPORL pretreated poplar without detoxification using a combined hydrolysis factor (CHF). Bioresour. Technol. 186, 223-231. doi:10.1016/j.biortech.2015.03.080

Zhou, H., Lan, T., Dien, B. S., Hector, R. E., and Zhu, J. Y. (2014a). Comparisons of five Saccharomyces cerevisiae strains for ethanol production from SPORL pretreated lodgepole pine. Biotechnol. Prog. 30, 1076-1083. doi:10.1002/btpr.1937

Zhou, H., Leu, S.-Y., Wu, X., Zhu, J. Y., Gleisner, R., Yang, D., et al. (2014b). Comparisons of high titer ethanol production and lignosulfonate properties by SPORL pretreatment of lodgepole pine at two temperatures. RSC Adv. 4, 27033-27038. doi:10.1039/c4ra03608e 
Zhou, H., Yang, D., Qiu, X., Wu, X., and Li, Y. (2013a). A novel and efficient polymerization of lignosulfonates by horseradish peroxidase/H2O2 incubation. Appl. Microbiol. Biotechnol. 97, 10309-10320. doi:10.1007/s00253-013-5267-1

Zhou, H., Zhu, J. Y., Luo, X., Leu, S.-Y., Wu, X., Gleisner, R., et al. (2013b). Bioconversion of beetle-killed lodgepole pine using SPORL: Process scale-up design, lignin coproduct, and high solids fermentation without detoxification. Ind. Eng. Chem. Res. 52, 16057-16065. doi:10.1021/ie402873y

Zhou, H., Zhu, J. Y., Gleisner, R., Qiu, X., Horn, E., and Negron, J. (2015). Pilot-scale demonstration of SPORL for bioconversion of lodgepole pine to bio-ethanol and lignosulfonate. Holzforschung doi:10.1515/hf-2014-0332

Zhu, J. Y., Chandra, M. S., Gu, F., Gleisner, R., Reiner, R., Sessions, J., et al. (2015). Using sulfite chemistry for robust bioconversion of Douglas-fir forest residue to bioethanol at high titer and lignosulfonate: a pilot-scale evaluation. Bioresour. Technol. 179, 390-397. doi:10.1016/j.biortech.2014.12.052

Zhu, J. Y., Gleisner, R., Scott, C. T., Luo, X. L., and Tian, S. (2011). High titer ethanol production from simultaneous enzymatic saccharification and fermentation of aspen at high solids: a comparison between SPORL and dilute acid pretreatments. Bioresour. Technol. 102, 8921-8929. doi:10.1016/j.biortech.2011.07.047

Zhu, J. Y., and Pan, X. J. (2010). Woody biomass pretreatment for cellulosic ethanol production: technology and energy consumption evaluation. Bioresour. Technol. 101, 4992-5002. doi:10.1016/j.biortech.2009.11.007

Zhu, J. Y., Pan, X. J., Wang, G. S., and Gleisner, R. (2009). Sulfite pretreatment (SPORL) for robust enzymatic saccharification of spruce and red pine. Bioresour. Technol. 100, 2411-2418. doi:10.1016/j.biortech.2008.10.057
Zhu, W., Houtman, C. J., Zhu, J. Y., Gleisner, R., and Chen, K. F. (2012). Quantitative predictions of bioconversion of aspen by dilute acid and SPORL pretreatments using a unified combined hydrolysis factor (CHF). Process Biochem. 47, 785-791. doi:10.1016/j.procbio.2012.02.012

Conflict of Interest Statement: Haifeng Zhou and Roland Gleisner are co-inventors of a US patent application on SPORL. The other co-authors declare that the research was conducted in the absence of any commercial or financial relationships that could be construed as a potential conflict of interest.

Received: 10 February 2015; paper pending published: 11 March 2015; accepted: 25 March 2015; published online: 27 April 2015.

Citation: Zhou H, Zhu JY, Gleisner R, Qiu X and Horn E (2015) High titer ethanol and lignosulfonate production from SPORL pretreated poplar at pilot scale. Front. Energy Res. 3:16. doi: 10.3389/fenrg.2015.00016

This article was submitted to Bioenergy and Biofuels, a section of the journal Frontiers in Energy Research.

Copyright ( $) 2015$ Zhou, Zhu, Gleisner, Qiu and Horn. This is an open-access article distributed under the terms of the Creative Commons Attribution License (CC BY). The use, distribution or reproduction in other forums is permitted, provided the original author(s) or licensor are credited and that the original publication in this journal is cited, in accordance with accepted academic practice. No use, distribution or reproduction is permitted which does not comply with these terms. 